\title{
Understanding the relationship between heavy metals in road-deposited sediments and washoff particles in urban stormwater using simulated rainfall
}

\author{
Hongtao Zhao, Xuyong Li* \\ State Key Laboratory of Urban and Regional Ecology, Research Center for Eco-Environmental Sciences, Chinese Academy of Sciences, Shuangqing Road 18, Beijing 100085, China
}

\section{H I G H L I G H T S}

- Heavy metal concentrations in washoff particles increased by 10-30\% compared with RDS.

- Rainfall intensity and duration did not affect increased rate of metal concentrations.

- Grain size of RDS and washoff particles carrying most heavy metals was different.

- Metal concentrations in RDS washoff decreased along the urban-rural gradient.

\section{A R T I C L E I N F O}

\section{Article history:}

Received 19 June 2012

Received in revised form

19 December 2012

Accepted 20 December 2012

Available online 28 December 2012

\section{Keywords:}

Particle size composition

Heavy metal chemical fraction

Simulated rainfall

Washoff process

Urban-rural gradient
G R A P H I C A L A B S T R A C T

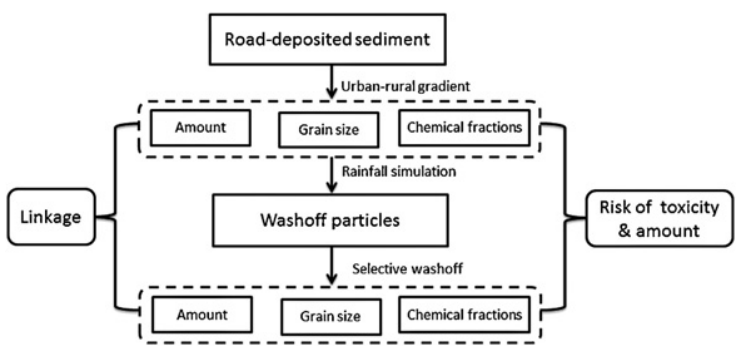

\begin{abstract}
A B S T R A C T
Understanding the relationship between heavy metals in road-deposited sediments (RDS) and washoff particles is essential to controlling urban runoff pollution. RDS and its associated heavy metals were investigated along the urban-suburban-rural gradient around Beijing, China. RDS washoff and its associated metal contaminants in different particle size fractions were evaluated using simulated rainfall. The results showed that the washoff percentage of RDS decreased along the urban-rural gradient. The $\mathrm{Cu}, \mathrm{Zn}$, $\mathrm{Ni}, \mathrm{Cr}$ and $\mathrm{Pb}$ contents in washoff particles were $28.1 \%, 20.0 \%, 19.7 \%, 11.6 \%$, and $11.4 \%$ higher than those in RDS, respectively. Additionally, different metals showed increases in different chemical fractions. RDS particles $<105 \mu \mathrm{m}$ accounted for $40 \%$ of the total mass in RDS, but $50 \%, 70 \%$ and $75 \%$ of the total metal content in RDS, washoff particle mass and washoff particle metal content, respectively. Rainfall intensity and duration affected the amount of metals in washoff, but did not lead to an increase in the percentage of metals with different chemical fractions in washoff particles. The findings presented herein will facilitate development of strategies for control of urban diffuse pollution from RDS.
\end{abstract}

(C) 2012 Elsevier B.V. All rights reserved.

\section{Introduction}

Road-deposited sediments (RDS) on impervious surfaces are important carriers of heavy metal contaminants that often contain metals at elevated concentrations [1,2]. Heavy metals washoff from RDS is an increasing problem associated with rapid urbanization that results in urban diffuse pollution [3,4]. Because of the difficulty associated with using natural rainfall events to investigate rigorous RDS washoff processes [5,6], washoff is the least

\footnotetext{
* Corresponding author. Tel.: +86 10 62849428; fax: +86 1062849428 .

E-mail address: xyli@rcees.ac.cn (X. Li).
}

understood among the three processes that occur before materials enter receiving waters (RDS buildup, washoff and transport) [7]. An in-depth understanding of these processes is essential to elucidation of the relationships of pollution between RDS and washoff particles $[8,9]$.

Both toxicity issues and the amount of metals in washoff particles should be considered when assessing the ecological risk to urban runoff posed by RDS. Knowledge of total metal concentration is insufficient for assessment of environmental risk [10]. Chemical fractions are critical to the evaluation of potentially toxic metals in RDS and washoff particles [11-13]. The amount, particle size and particles mobility of RDS strongly affect their potential contribution to washoff particles. However, most 
Table 1

Characteristics of different administrative divisions along the urban-rural gradient.

\begin{tabular}{|c|c|c|c|c|c|}
\hline Sampling sites ${ }^{\mathrm{a}}$ & $\begin{array}{l}\text { Population density } \\
\left(\text { person } / \mathrm{km}^{2}\right)^{\mathrm{b}}\end{array}$ & $\begin{array}{l}\text { Average daily traffic } \\
(\text { vehicle } / \mathrm{d} / \mathrm{m})^{\mathrm{c}}\end{array}$ & $\begin{array}{l}\text { Total energy consumption (1000 } \\
\text { tons of SCE) }{ }^{\mathrm{d}}\end{array}$ & $\begin{array}{l}\text { Street cleaning } \\
\text { method }^{\mathrm{e}}\end{array}$ & $\begin{array}{l}\text { Frequency of sweeping } \\
\text { (times/d) }^{\mathrm{f}}\end{array}$ \\
\hline UCA (11) & 15,000 & 8900 & 960 & M & 3 \\
\hline UVA (6) & 1200 & 115 & 346 & $\mathrm{H}$ & $<0.2$ \\
\hline $\operatorname{CSA}(40)$ & $3000-5000$ & 6700 & 960 & M & $3-2$ \\
\hline RTA (20) & $1500-2000$ & 1300 & 346 & $\mathrm{H}$ & 2 \\
\hline RVA (20) & 1000 & 105 & 346 & $\mathrm{H}$ & 0.3 \\
\hline
\end{tabular}

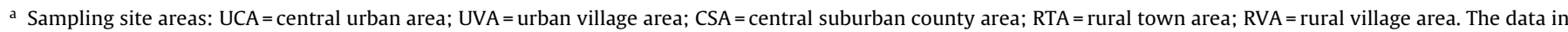
parentheses is the number of sampling sites.

b Population density was estimated using the data from Beijing Municipal Bureau of Statistics in Beijing.

c Average daily traffic was estimated using the data from Beijing Transportation Research. The data was divided by lane-width of road in order to compare each other.

d The energy consumption refers to residential consumption, including coal, gasoline, diesel oil, liquefied petroleum gas, natural gas, heat, and electricity. It was estimated

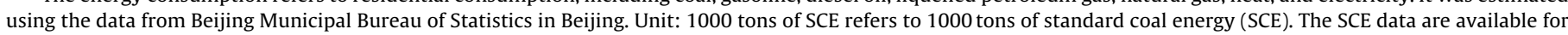
only categories: the urban and rural areas.

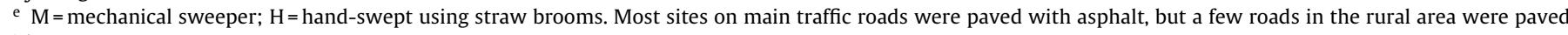
with concrete.

f Street cleaning methods and frequency were based on our in situ investigation.

previous studies have investigated metal contaminants in RDS [14-16] and washoff particles [17-19] separately, or chemical fractions in RDS $[20,21]$. Indeed, few studies have investigated the pollutant chemical fractions of different particle sizes in RDS and washoff particles or their relationship. Accordingly, there is a clear need to investigate the relationship between the amount, particle size distribution and proportion of different metal chemical fractions in RDS with washoff particles, so that we can better understand how RDS affects heavy metal pollution through urban runoff.

The urban-suburban-rural gradient pattern is has been strongly affected by rapid urbanization in China, and in turn affects land use zoning, population density, proportion of impervious surfaces, traffic density, energy consumption, street cleaning methods, and spatial distribution of manufacturers $[6,22]$. Therefore, the urban-rural gradient could affect the amounts and proportions of different chemical fractions of heavy metals in RDS and washoff particles by influencing the particle size of RDS, the metals associated with RDS and the RDS washoff process. In this study, a washoff experiment was conducted using simulated rainfall and RDS samples collected from the studied area. Simulated rainfall provided greater flexibility and control of the fundamental rainfall parameters such as intensity and duration. Both RDS samples and washoff particle samples were analyzed for the amounts, particle size composition and concentrations of metals with different chemical fractions on each particle size. Specifically, we investigated how the RDS from an urban-rural gradient affect concentrations of heavy metals with different chemical fractions in washoff particles.

\section{Materials and methods}

\subsection{Study area and RDS sampling}

The administrative division in China has historically consisted of five practical levels: the province, prefecture, county, township, and village [23]. A province consists of a group of prefectures, a prefecture consists of a group of counties, a county consists of a group of townships, and a township consists of villages. This administrative division is defined by political boundaries but is not defined by any quantified criteria. The division in large cities follows similar patterns. In general, a large city in China is divided along urban, suburban, and rural areas as follows: urban district, suburban county, rural township, rural village and urban village. Legally, an urban district is equivalent to a county. An urban village is located within an urban area but is still more similar to a rural village in that it lacks urban infrastructure and services [24]. Such a division has a remarkable urban-suburban-rural function gradient. Our RDS samples were collected from each of the administrative divisions in the Beijing metropolitan region. These administrative division units are called a central urban area (UCA) within the urban district, a central suburban county area (CSA) within a suburban county, a rural town area (RTA) within a rural township, a rural village (RVA) area and an urban village area (UVA) [6]. The series UCA, CSA, RTA, RVA and UVA has an urban-rural gradient feature with a gradient variation through different administrative divisions, and differ in characteristics such as population density, average daily traffic, total energy consumption, the method of street cleaning and street cleaning frequency (Table 1 ).

RDS samples were collected using a domestic vacuum cleaner (Philips FC8264) during September 2-10, 2009, which followed an antecedent dry period of about 2 weeks. This vacuum cleaner had high efficiency with an air filtration system and a cyclonic dustbin that effectively captures microscopic particulates. The RDS sampling sites were distributed along main traffic roads with the following urban-suburban-rural gradient: UCA, UVA, CSA, RTA, and RVA (Table 1). To account for variation in RDS characteristics on roads of areas, the number of sampling sites varied depending on our field investigation (Table 1 ). For example, we selected four main traffic roads as our sampling sites of the CSA for each of the ten suburban counties. We collected the RDS from all the ten suburban counties so that we could assure our sampling sites cover all suburban counties. The total sampling site number at the CSA was 10 CSA areas $\times 4$ main traffic roads $=40$ sampling sites. Based on our on-site investigation, we found that the characteristics of the UCA RDS had relatively lower variation. Eleven sampling sites were selected to represent the major roads of the UCA. Because of the smaller area of RTA and lower RDS variation of the RTA, RVA and UVA, we selected 20 (10 RTA $\times 2$ main traffic roads), 20 ( $10 \mathrm{RVA} \times 2$ main traffic roads $)$ and 6 ( 3 UVA $\times 2$ main traffic roads) sampling sites, for RTA, RVA, and UVA, respectively. We collected RDS samples (1) during a dry weather period of about 2 weeks; (2) at a time that was half-way between the last sweeping time and the next; (3) so that the collection of all RDS samples in the study were completed in as short a time period as possible (eight days in this study). For each RDS sample collection, a variable area was vacuumed from the central road marking to the curb, after which the sampling area size was measured with a ruler. All RDS samples were dried at room temperature for 7 days, and then weighed using an electronic scale. The sample mass ranged from 0.8 to $1.5 \mathrm{~kg}$. Samples were sorted into particle size fractions of $<44,44-62,62-105,105-149,149-250$, 250-450, 450-1000 and $>1000 \mu \mathrm{m}$ using polyester sieves, which are typically referred to as silt and clay, very fine sand, fine sand, medium sand, coarse sand, and very coarse sand, respectively [3]. 


\subsection{Experimental design of RDS washoff by rainfall simulation}

The rainfall simulation was designed according to Herngren et al. (2005), Egodawatta et al. (2007), and Xie et al. (2008) [5,7,25]. The device consisted of two rainfall simulators. The four nozzles of the two rainfall simulators were equally distributed (with an interval of $1.1 \mathrm{~m}$ ) along the swing nozzle boom, which stood at $2.5 \mathrm{~m}$ above the ground. The rainfall simulators were operated using an electronic control box that enabled calibration for different rainfall intensities. To reproduce natural rainfall characteristics as closely as possible, the water used in the simulated rainfall was measured and adjusted. The $\mathrm{pH}$ value and electrical conductivity (EC) of water used in the rainfall simulation was $6.0 \pm 1.2$ and $100 \pm 80 \mu \mathrm{s} / \mathrm{cm}$, respectively, which was close to that of natural rainfall in the Beijing region ( $\mathrm{pH}: 5.50 \pm 1.80$; EC: $80 \pm 65 \mu \mathrm{s} / \mathrm{cm}$ ). The nozzles (Veejet 80100) generated uniform raindrops with medium sizes at a constant pressure of $0.04 \mathrm{Mpa}$. The two rainfall simulators generated a total uniform rainfall area of $1.5 \mathrm{~m} \times 2.2 \mathrm{~m}$. We selected an area of $1.5 \mathrm{~m} \times 2.0 \mathrm{~m}$ as our washoff test plot. A $1.5 \mathrm{~m} \times 2.0 \mathrm{~m}$ plastic frame was used to demarcate the plot boundary, which was sealed with a paved surface. One end of the plastic frame was kept open to affix the catch tray used for runoff collection.

The road selected for the RDS washoff experimental plot was paved with asphalt 2 years prior to the experiment, and its roughness and slope were $0.625 \mathrm{~mm}$ and $2.36^{\circ}$, respectively. The RDS was spread uniformly throughout the washoff plot prior to the test.

To obtain representative samples from our simulated runoff experiment, we used mixed RDS samples that were collected throughout the study area. Samples with an RDS fraction $<250 \mu \mathrm{m}$ $(<44,44-62,62-105,105-149,149-250 \mu \mathrm{m})$ were obtained from the UCA and CSA sites, while those $>250 \mu \mathrm{m}$ (250-450 and 450-1000 $\mu \mathrm{m}$ ) were collected from the RVA and UCA sites. Further details regarding the experimental design are available elsewhere (Supporting Information; Zhao et al., 2011) [6].

In our RDS washoff experiment, $20 \mathrm{~g} / \mathrm{m}^{2}$ of RDS sample for each individual RDS fraction from seven size fractions $(<44,44-62$, $62-105,105-149,149-250,250-450$ and $450-1000 \mu \mathrm{m})$ were washed off using three simulated rainfall intensities (12.87, 46.7 and $82.67 \mathrm{~mm} / \mathrm{h}$ ) applied for $1 \mathrm{~h}$ each (Table 2). Therefore, there were 21 different washoff scenarios.

During the washoff experiment, surface runoff samples were collected and their volumes were measured at set intervals for each simulated rainfall event (Table 2). Each size fraction of RDS in the runoff from the impervious surface was expressed as a percentage of the total RDS mass in the runoff with respect to the initial total mass of RDS on the surface. This was calculated by the following equation [6]:

$F_{w}(\%)=\frac{M_{F_{w}}}{M_{\text {initial }}} \times 100 \%=\frac{\int_{0}^{1} C(t) \times Q(t) d t}{M_{\text {initial }}} \times 100 \%$

where $F_{w}$ is the percentage of each RDS size fraction washed off the surface (\%); $M_{F_{w}}$ is the mass of the size fraction washed off the surface over the entire rain event (mg); $M_{\text {initial }}$ is the initial mass of RDS with a corresponding particle size on the surface (mg); $C(t)$ is the mass of RDS with a corresponding particle size in the surface runoff water $(\mathrm{mg} / \mathrm{L})$ at each sampling time; and $Q(t)$ is the surface runoff flow rate at each sampling time $\left(\mathrm{m}^{3} / \mathrm{min}\right)$.

$F_{w}$ was used to calculate the amount and size composition of the washoff particles, as well as the concentrations of different chemical fractions of metals associated with the washoff particles. Because the washoff proportion of each RDS size fraction $\left(F_{w}\right)$ was independent of the amount and particle size composition [26], we adjusted the amount and particle size composition of RDS to those in the corresponding sampling units to represent the RDS washoff scenarios in our washoff calculations. We applied $F_{w}$ values of all individual RDS size fractions to deduce the RDS washoff amount for the RDS samples from urban-rural gradient units of UCA, UVA, CSA, RTA, and RVA.

\subsection{Estimation of heavy metal loads in RDS}

To determine the contribution particle sizes to the overall contamination of the RDS, we calculated the pollutant load percentage for each individual RDS sample. The particle size fraction load $\left(\mathrm{GSF}_{\text {Load }}\right)$ was calculated using the following equation [3]:

$$
\mathrm{GSF}_{\text {Load }}=\frac{C_{i} \times G S_{i}}{\sum_{i=1}^{n} C_{i} \times G S_{i}}
$$

where $C_{i}$ is the heavy metal level associated with a RDS sample for a given particle size $(\mathrm{mg} / \mathrm{kg}) ; G S_{i}$ is the percentage by mass of the size fraction $i$ in the total sample (\%); and $n$ is the number of particle size fractions.

\subsection{Estimation of heavy metal concentration in washoff particles}

There are many important factors that impact the potential contribution of RDS to surface runoff and runoff pollution. In the RDS runoff experiment, we focused on RDS particle size and particle size composition. The RDS percentage contribution for different particle sizes could be calculated from the combination of each particle size percentage. We used the following equation to calculate the concentration of heavy metal in washoff particles:

$$
C_{s}=\frac{\sum_{i=1}^{n} M_{i} \times C_{i} \times F_{w i}}{\sum_{i=1}^{n} M_{i} \times F_{w i}}
$$

Table 2

\begin{tabular}{|c|c|c|}
\hline Rainfall intensity & Sampling interval $^{\mathrm{b}}$ & Particle size fraction of RDS \\
\hline $12.87 \mathrm{~mm} / \mathrm{h}$ & $0-2,2-4,4-6,6-8,8-10,10-15,15-20,20-30,30-40,40-50,50-60 \mathrm{~min}$ & $<44,44-62,62-105,105-149,149-250,250-450,450-1000 \mu \mathrm{m}$ \\
\hline $46.7 \mathrm{~mm} / \mathrm{h}$ & $0-2,2-4,4-6,6-8,8-10,10-15,15-20,20-30,30-40,40-50,50-60 \mathrm{~min}$ & $<44,44-62,62-105,105-149,149-250,250-450,450-1000 \mu \mathrm{m}$ \\
\hline $82.67 \mathrm{~mm} / \mathrm{h}$ & $0-2,2-4,4-6,6-8,8-10,10-15,15-20,20-30,30-40,40-50,50-60 \mathrm{~min}$ & $<44,44-62,62-105,105-149,149-250,250-450,450-1000 \mu \mathrm{m}$ \\
\hline
\end{tabular}

Simulated rainfall intensities, rainfall durations and particle size fraction of RDS in the RDS washoff experiment ${ }^{\mathrm{a}}$.

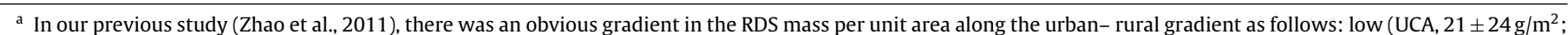

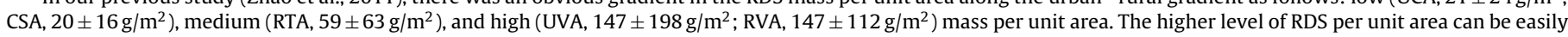

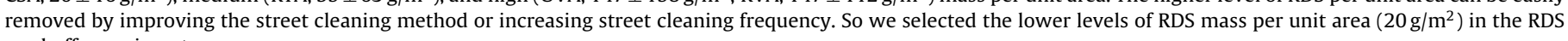
washoff experiment.

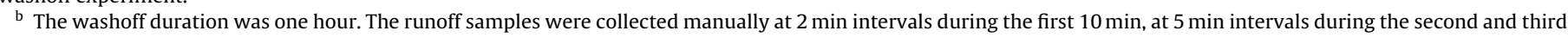
$10 \mathrm{~min}$, and at $10 \mathrm{~min}$ intervals thereafter until there was no more surface runoff. 


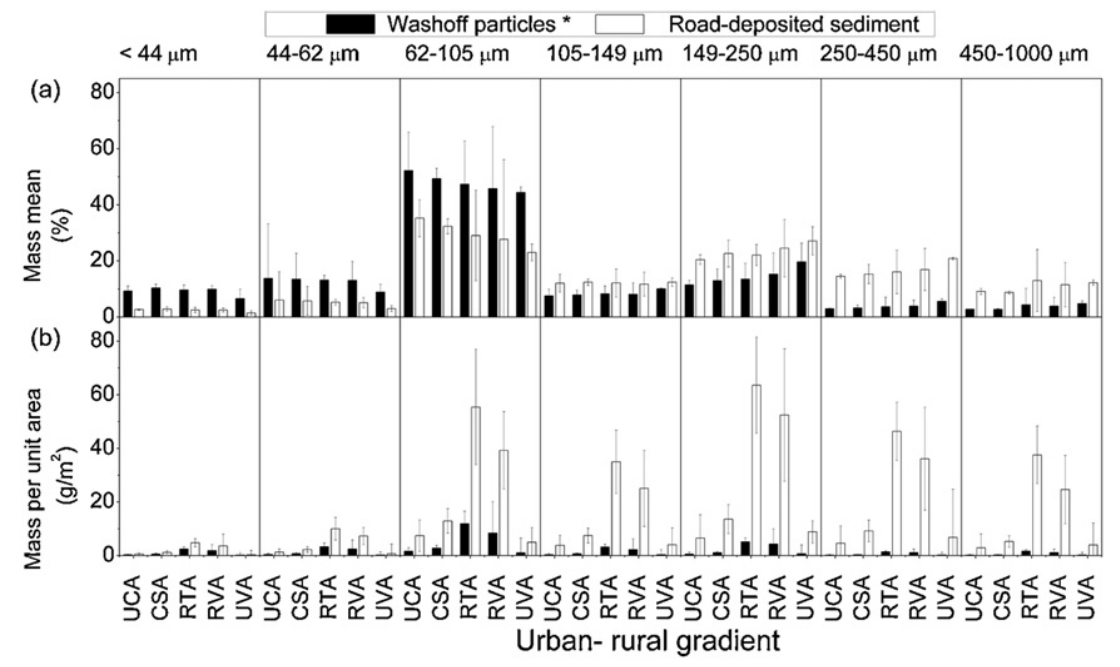

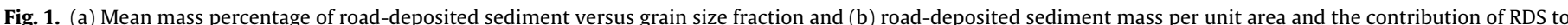

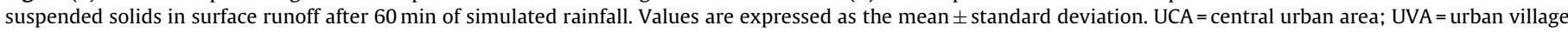

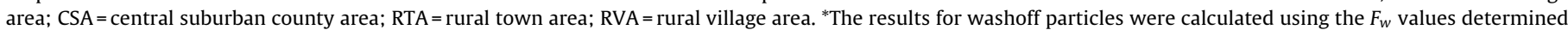
with a rainfall intensity of $46.7 \mathrm{~mm} / \mathrm{h}$ and duration of $1 \mathrm{~h}$. The detailed method for calculation is provided in Section 2.3 .

where $C_{S}$ is the metal content in washoff particles $(\mathrm{mg} / \mathrm{kg}) ; M_{i}$ is the initial mass of RDS with a corresponding particle size on the surface (mg); $C_{i}$ is the heavy metal level associated with a RDS sample for a given particle size $(\mathrm{mg} / \mathrm{kg}) ; F_{w}$ is the percentage of each RDS size fraction washed off the surface (\%); and $n$ is the number of particle size fractions.

\subsection{Analytical methods}

The BCR protocol developed by the Standard Measurement and Testing Program of the European Community [27,28] and the optimized BCR sequential extraction procedure developed by Sutherland and Tack(2002) [29] were used to fractionate the metals into the following target phases: acid-extractable (water soluble, exchangeable and bound to carbonate), reducible (bound to amorphous Fe-and Mn-oxides), oxidizable (bound to organic matter), and residual (bound to minerals). This procedure included four steps: (1) acid-extractable: extraction of $1.00 \mathrm{~g}$ RDS sample by adding $40 \mathrm{~mL} 0.11 \mathrm{M}$ acetic acid; (2) reducible: addition of $40 \mathrm{~mL}$ $0.5 \mathrm{M} \mathrm{NH}_{2} \mathrm{OH}^{\bullet} \mathrm{HCl}(\mathrm{pH} \approx 1.5)$; (3) oxidizable: addition of $10 \mathrm{~mL}$ $\mathrm{H}_{2} \mathrm{O}_{2}$ ( $\mathrm{pH} 2-3$ ) to the sample followed by incubation for $1 \mathrm{~h}$ at room temperature, and then at $85 \pm 2{ }^{\circ} \mathrm{C}$ for $1 \mathrm{~h}$, after which $10 \mathrm{~mL}$ of $\mathrm{H}_{2} \mathrm{O}_{2}$ are added and the sample is incubated at $85 \pm 2{ }^{\circ} \mathrm{C}$ for $1 \mathrm{~h}$ and $50 \mathrm{~mL} 1 \mathrm{M} \mathrm{NH}_{4} \mathrm{OAc}(\mathrm{pH} 2$ ) are added; (4) residual: addition of $3 \mathrm{~mL}$ distilled $\mathrm{H}_{2} \mathrm{O}, 7.5 \mathrm{~mL} 6 \mathrm{M} \mathrm{HCl}$, and $2.5 \mathrm{~mL} 14 \mathrm{M} \mathrm{HNO}_{3}$ followed by overnight incubation at $20^{\circ} \mathrm{C}$, then boiling under reflux for $2 \mathrm{~h}$, cooling and filtration. After each of the first three steps, the suspension was shaken for $16 \mathrm{~h}$ at $22 \pm 5^{\circ} \mathrm{C}$ and the extract was then separated from the solid residue by centrifugation at $3000 \mathrm{rpm}$ for $20 \mathrm{~min}$. Total metals were measured after digestion with $\mathrm{HF}-\mathrm{HClO}_{4}$ on a hotplate [30]. GBW07401(GSS-1) and GBW07402(GSS-2), which are the General Administration of Quality Supervision, Inspection and Quarantine of the PR China certified reference materials (CRMs) for soil, were used as the CRMs for digestion of RDS. The mass balance was evaluated by comparing the total metal content with the sum of the metal fractions. All solutions were stored at $4{ }^{\circ} \mathrm{C}$ prior to analysis. The concentrations of $\mathrm{Cr}, \mathrm{Cu}, \mathrm{Ni}, \mathrm{Pb}$ and $\mathrm{Zn}$ were determined using a PerkinElmer Elan 6000 ICP-OES. For heavy metal analysis, recoveries varied, but all fell within the range of $75-110 \%$. The precision was nearly $90 \%$ with a confidence level of $95 \%$

\section{Results}

\subsection{Particle size distribution of RDS and washoff particles}

Particle size composition is critical to assessment of the role of RDS and washoff particles in heavy metal pollution of urban runoff. RDS particles with a particle size of $62-105 \mu \mathrm{m}$ were the most abundant among the seven size fractions, accounting for $33 \pm 14 \%$ of the total (Fig. 1a). When compared to the mass percentage of RDS with a corresponding particle size on the surface, washoff particles with less than $105 \mu \mathrm{m}$ were present in higher proportions. Particles with particle sizes less than $105 \mu \mathrm{m}$ in RDS particles and washoff particles accounted for $27-44 \%$ and $60-75 \%$ of the total mass of RDS particles and washoff particles, respectively. This resulted from washoff selectively transporting RDS of particular particle sizes.

The potential contribution of RDS washed off per unit area of impervious surface to runoff was determined by the amount of RDS per unit area. This value was calculated based on the simulated rainfall event (unit: $\mathrm{mg} / \mathrm{m}^{2}$ ) and found to be: RVA $(18.4 \pm 24.7)>$ UVA $(16.0 \pm 11.9)>$ RTA $(7.6 \pm 8.3)>$ UCA $(3.0 \pm 2.4)>\operatorname{CSA}(2.8 \pm 2.1)$ (Fig. 1b). In addition, the $F_{w}(\%)$ for entire particular particle sizes along the urban-rural gradient was estimated to be: UCA $(15.8 \pm 2.7 \%)>$ CSA $(14.2 \pm 1.6 \%)>$ RVA $(13.5 \pm 2.5 \%)>\operatorname{RTA}(12.7 \pm 2.2 \%)>$ UVA $(11.6 \pm 1.7 \%)$, which was determined based on the particle size composition of RDS collected from areas in five administrative units.

\subsection{Comparison of heavy metal concentration with different chemical fractions in RDS and washoff particles}

Comparison of the heavy metal distribution in RDS and washoff particles is important to understand runoff pollution as a result of RDS. Heavy metal concentrations with different chemical fractions in washoff particles were generally higher than those in RDS (Fig. 2). The percentage of total metals in washoff particles compared with that in RDS was as follows: $\mathrm{Cu}(28.1 \pm 8.2 \%)>\mathrm{Zn}$ $(20.0 \pm 11.7 \%)>\mathrm{Ni}(19.7 \pm 9.4 \%)>\mathrm{Cr}(11.6 \pm 7.4 \%)>\mathrm{Pb}(11.4 \pm 2.6 \%)$. The increases in total metal concentrations were attributed to increases of different chemical fractions. The residual, oxidizable, acid-extractable and residual, oxidizable and residual, acid-extractable and reducible chemical fractions were the main 


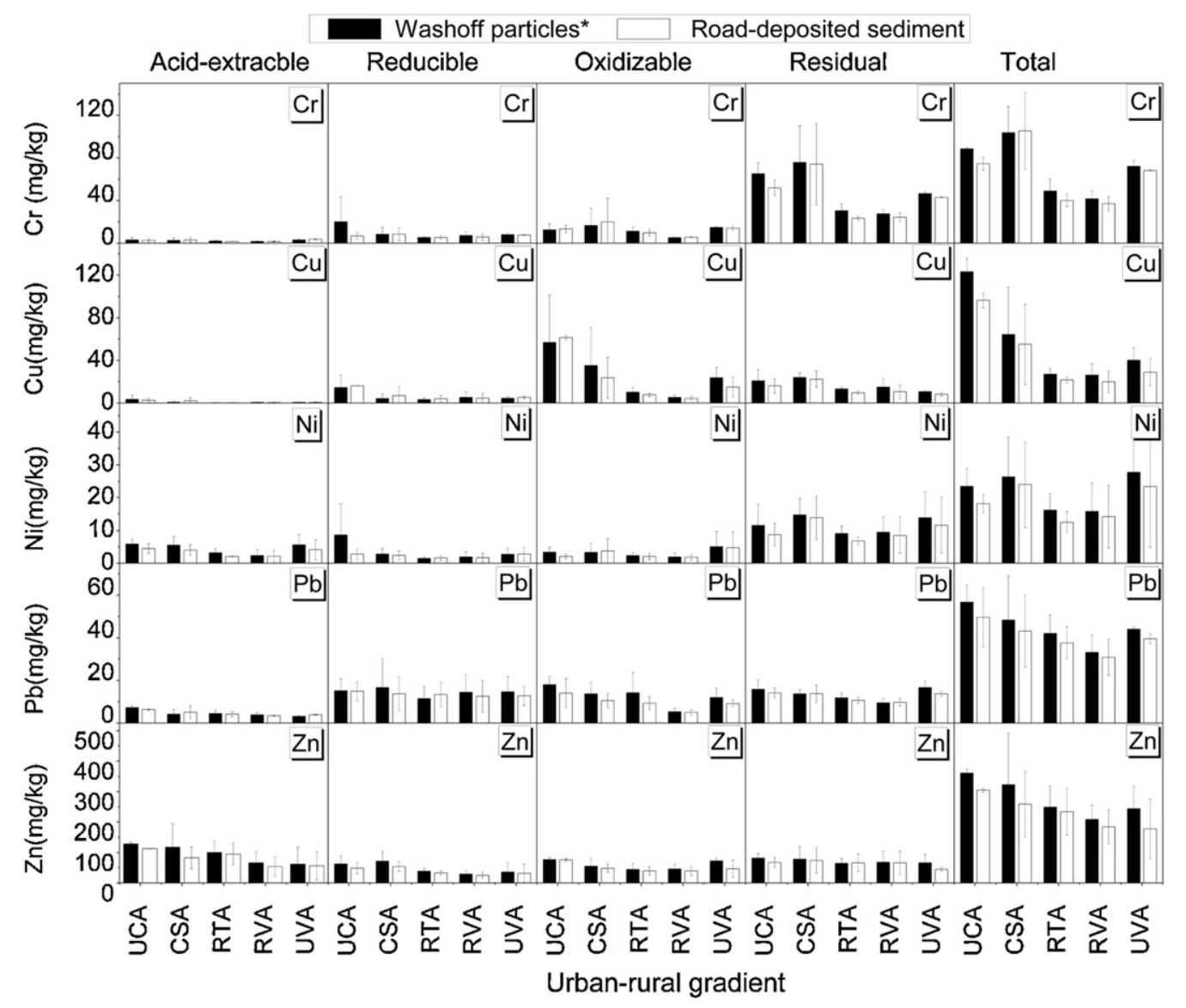

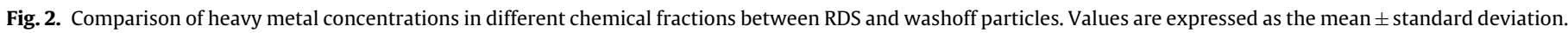

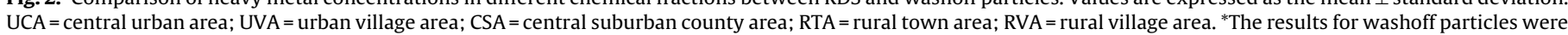
calculated using the $F_{w}$ values determined with a rainfall intensity of $46.7 \mathrm{~mm} / \mathrm{h}$ and duration of $1 \mathrm{~h}$. The detailed method for calculation is provided in Section 2.3 .

contributors to the increased percentage of total concentrations of $\mathrm{Cr}, \mathrm{Cu}, \mathrm{Ni}, \mathrm{Pb}$ and $\mathrm{Zn}$, respectively. The ratio of the mobile phase (the sum of acid-extractable, reducible, and oxidizable fractions) to the total concentration in RDS was in the following order: $\mathrm{Zn}(72.1 \pm 5.2 \%)>\mathrm{Pb}(68.9 \pm 2.7 \%)>\mathrm{Cu}(63.3 \pm 14.4 \%)>\mathrm{Ni}$ $(45.9 \pm 5.1 \%)>\mathrm{Cr}(34.6 \pm 4.9 \%)$, while those in washoff particles followed a similar pattern: $\mathrm{Zn}(73.5 \pm 3.7 \%)>\mathrm{Pb}(69.7 \pm 4.3 \%)>\mathrm{Cu}$ $(62.5 \pm 16.3 \%)>\mathrm{Ni}(45.7 \pm 4.7 \%)>\mathrm{Cr}(32.0 \pm 5.1 \%)$. The difference in pollutant distribution between RDS and washoff particles was caused by their particle size composition.

\subsection{Impacts of particle sizes on metal contamination in RDS and washoff water}

The particle size composition of RDS and washoff particles also determines the contribution of particles with different particle sizes to the overall contamination. We estimated the contribution of particles with different particle sizes to the overall contamination of RDS and washoff particles using the $\mathrm{GSF}_{\text {Load }}$ (Fig. 3). For RDS, the order of the mean $\mathrm{GSF}_{\text {Load }}$ values for all total metals combined was $62-105 \mu \mathrm{m} \quad(37 \pm 10 \%)>149-250 \mu \mathrm{m}$ $(19 \pm 8 \%)>105-149 \mu \mathrm{m}$

$(14 \pm 5 \%)>250-450 \mu \mathrm{m}$ $(10 \pm 6 \%)>44-62 \mu \mathrm{m}(9 \pm 5 \%)>450-1000 \mu \mathrm{m}(6 \pm 5 \%)>0-44 \mu \mathrm{m}$ $(4 \pm 2 \%)$, while for washoff particles the order was $62-105 \mu \mathrm{m}$ $(48 \pm 13 \%)>44-62 \mu \mathrm{m} \quad(15 \pm 10 \%)>0-44 \mu \mathrm{m} \quad(12 \pm 4 \%) \approx$ $149-250 \mu \mathrm{m} \quad(12 \pm 9 \%)>105-149 \mu \mathrm{m} \quad(11 \pm 2 \%)>250-450 \mu \mathrm{m}$ $(2 \pm 2 \%) \approx 450-1000 \mu \mathrm{m}(2 \pm 2 \%)$. RDS with a particle size $<100 \mu \mathrm{m}$ is commonly referred to as the particle size of suspended solids in runoff [31]. Consequently, the contribution of particles $<105 \mu \mathrm{m}$ in diameter to the overall metal contamination of the RDS affected the potential release to runoff pollution. RDS particles $<105 \mu \mathrm{m}$ accounted for $40 \%$ of the total mass in RDS, but $50 \%, 70 \%$ and $75 \%$ of the total metals content in RDS, washoff particle mass and washoff particles, respectively. Street sweepers have been shown to be less efficient in picking up particles with low particle size, which implies that it is difficult to remove most of the metal load in stormwater runoff by conventional street sweepers [6,32,33].

The percentages of contributions of the RDS particle size fractions to the total mean $\mathrm{GSF}_{\text {Load }}$ of all metals were calculated along the urban-rural gradient (Table 3 ). For RDS and washoff particles, particles with a particle size $<105 \mu \mathrm{m}$ contributed $20-30 \%$ and $50-90 \%$ of the heavy metal loads including the four chemical fractions (acid-extractable, reducible, oxidizable, and residual), respectively. The above results were basically consistent with those of a previous study conducted by Sansalone and Ying (2008) that the finer particles generates the highest metal concentrations and the highest metal mass is associated with the coarser fraction [34]. The RDS and washoff particles with particle size $<105 \mu \mathrm{m}$ in UCA and

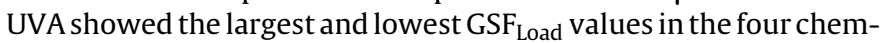
ical fractions, respectively, based on the particle size composition and pollutant distribution associated with them.

\subsection{Estimation of amounts of metals from RDS in runoff}

The potential heavy metal contribution of surface runoff is impacted by the mobility of RDS particles with different particle size and the metal distribution in the corresponding particle size. The metals mass per unit area varied widely as follows (unit: 


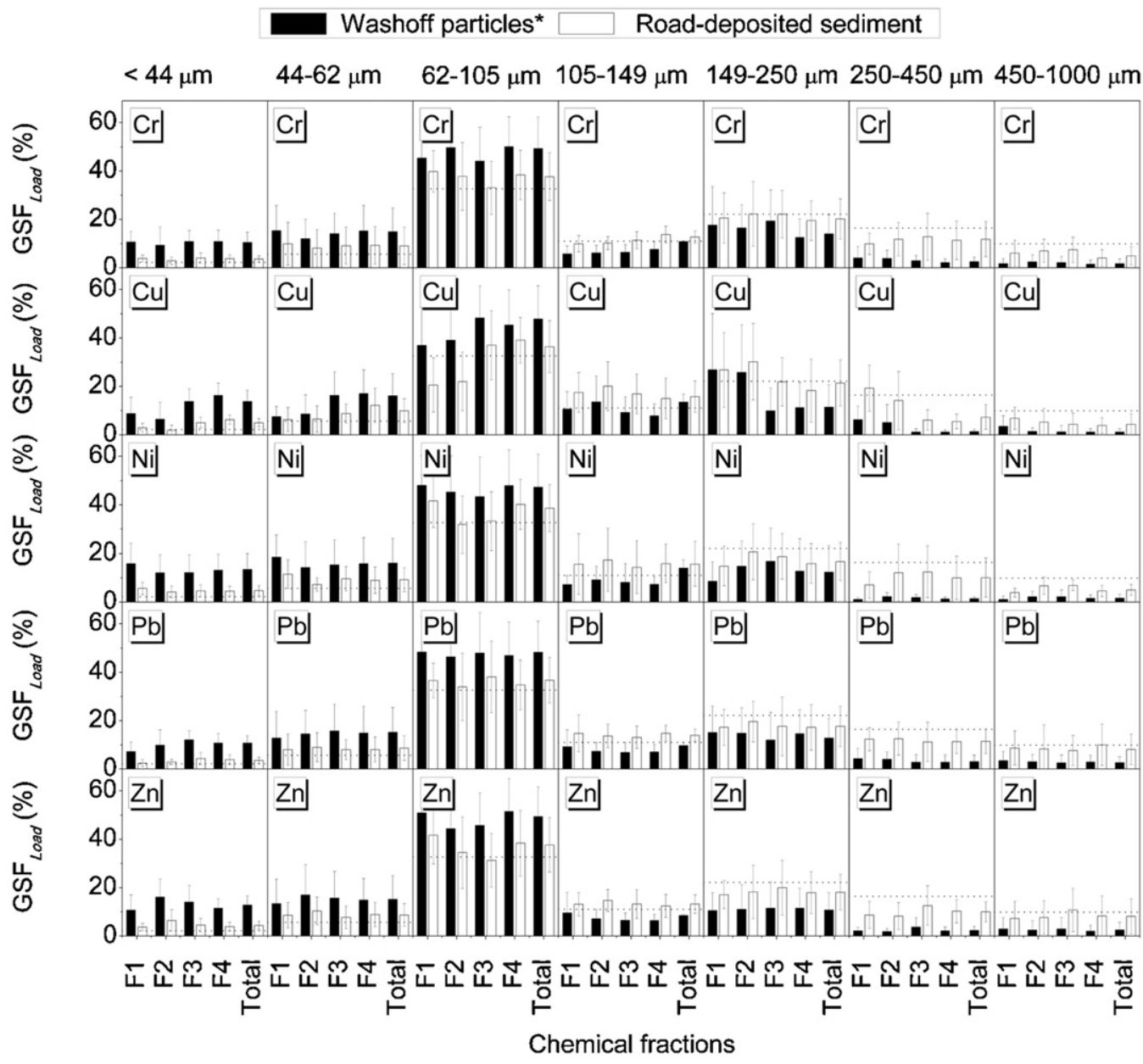

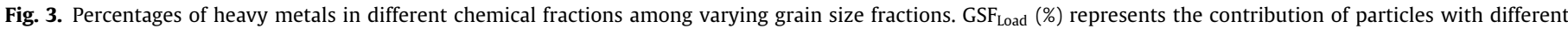

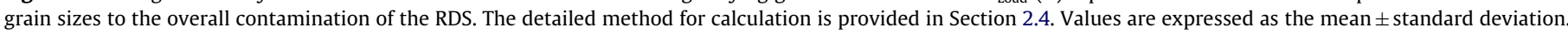

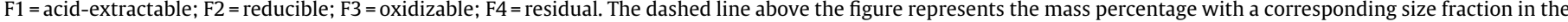
total RDS.

$\left.\mu \mathrm{g} / \mathrm{m}^{2}\right)$ : total $\mathrm{Cr} 400-3500$, total Cu 80-4000, total Ni 200-4000, total $\mathrm{Pb} 200-4500$ and total $\mathrm{Zn} 1500-25000$ (Fig. 4). The proportion of potential contribution in surface runoff accounting for total metal load in RDS per unit area was approximately 10-25\%. RVA and RTA had the largest metal load per unit area in RDS and washoff particles. However, the largest proportion of potential washoff metal load was observed in UVA and CSA. Approximately $60-75 \% \mathrm{Cu}$, $\mathrm{Pb}$ and $\mathrm{Zn}$ in washoff particles per unit area were stored in the mobile phase (the sum of acid-extractable, reducible, and oxidizable fractions). The above results implied that different controlling strategies for RDS pollution could be applied along the urban-rural gradient.

\subsection{Impacts of rainfall intensity and duration on heavy metal concentrations with different chemical fractions in washoff particles}

In our experimental design, the rainfall intensities of 12.87 , 46.7 and $82.67 \mathrm{~mm} / \mathrm{h}$ represented the typical rainfall intensity classes of moderate, intensive and highly intensive according to rainfall intensity class in Beijing, respectively. The rainfall durations of $0-10$ and $0-60 \mathrm{~min}$ represent the periods of the first flush and the entire washoff process during a typical rainfall event, respectively. The results of a case study in a central urban area suggested that metal concentrations with different chemical fractions in washoff particles were basically coincident during the washoff process (Table 4). The difference in metal concentrations between RDS and washoff particles with different chemical fractions was not affected by rainfall intensity or duration. These findings implied that the amount of washoff particles varied with different rainfall intensities and durations, but that the particle size composition of the washoff particles was not influenced.

\section{Discussion}

Quantifying the relationship between RDS and washoff particles is important for estimation of the pollution load and assessment of the ecological risk that a waterway receives. Particle size composition is a critical factor in this relationship because surface washoff selectively transports RDS of particular particle sizes [12,13]. The washoff percentage of each RDS size fraction $\left(F_{w}\right)$ varies with the particle size of RDS, with smaller particle sizes being associated with higher values of $F_{w}$. Washoff particles have higher proportions of smaller particle sizes than those in RDS. Previous studies suggested that RDS and washoff particles had either an exponential, rating curve, or other relationship depending on a range of parameters such as surface characteristics, rainfall intensity and duration, RDS particle sizes, land use, etc. [7,9,33-37]. However, it was unclear how particle size composition influenced the relationship of pollutants between RDS and washoff particles [38] We compared heavy metals concentrations with different chemical 


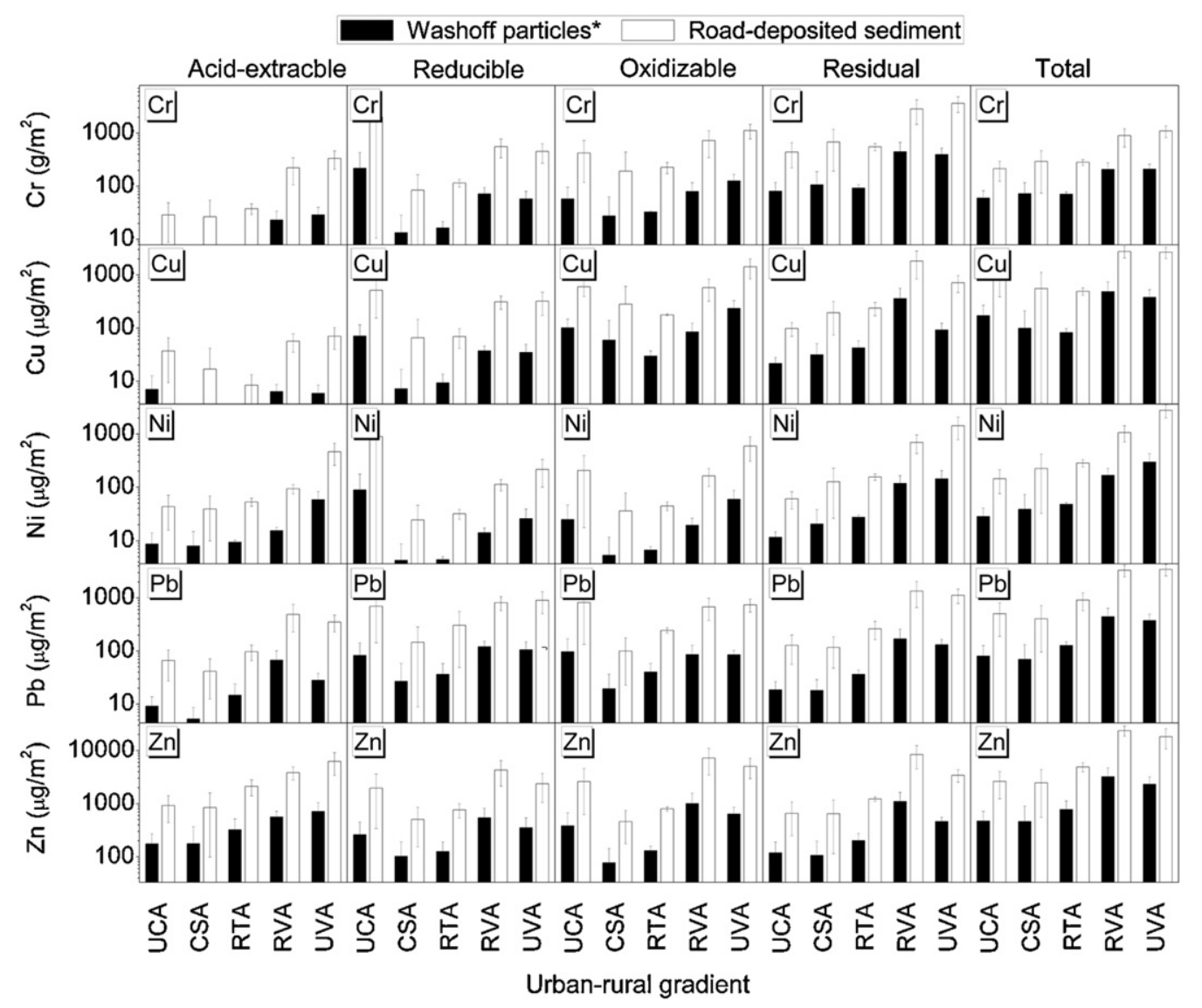

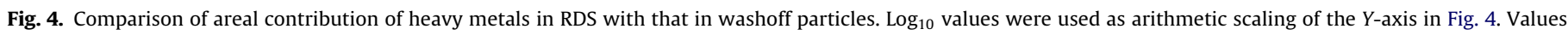

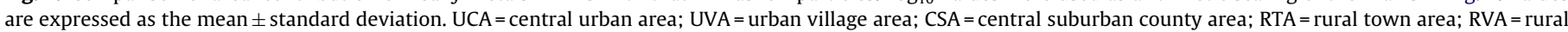
village area. Results for washoff particles in Fig. 4 were calculated using the specific $F_{w}$ values determined with a rainfall intensity of $46.7 \mathrm{~mm} / \mathrm{h}$ and duration of $1 \mathrm{~h}$.

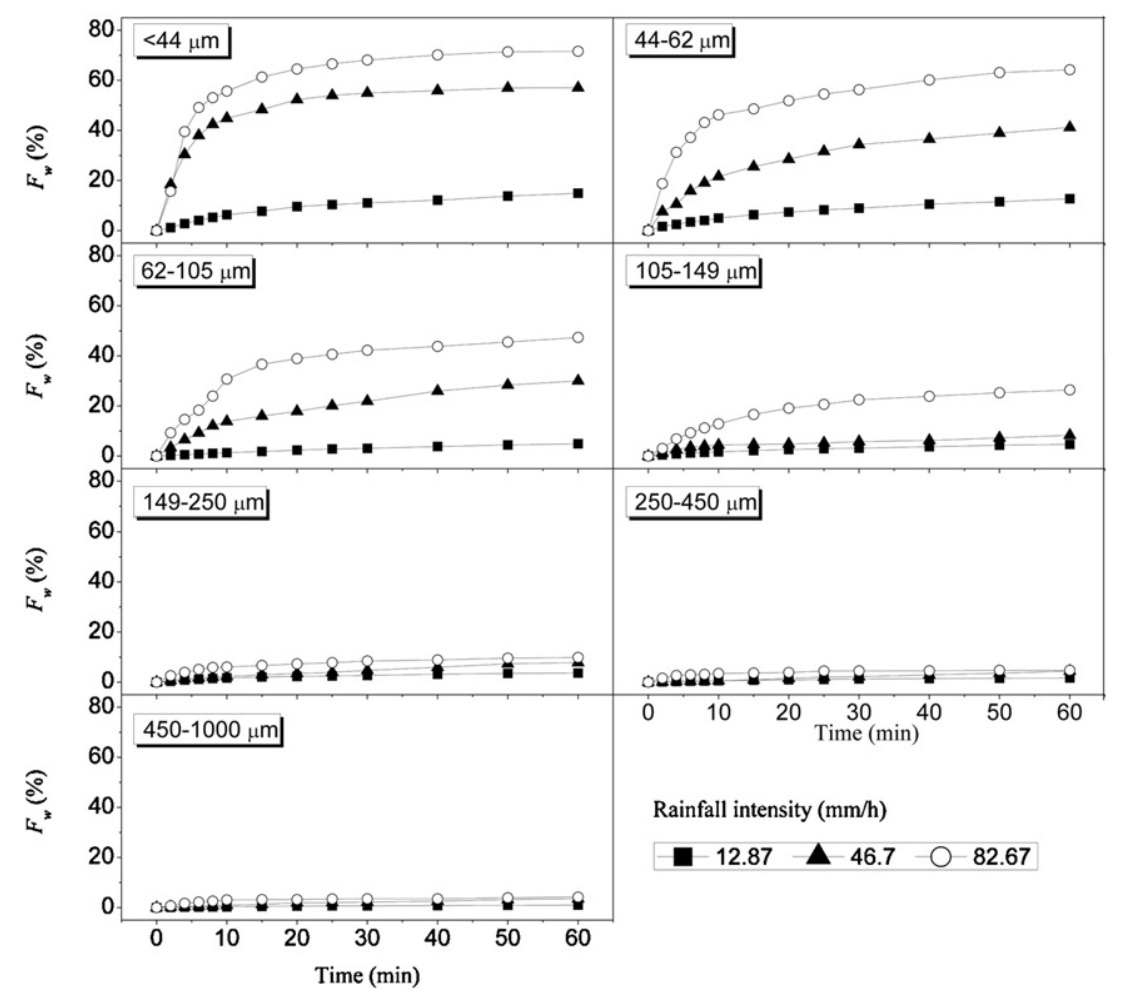

Fig. 5. Impacts of rainfall intensity and duration on the washoff percentage of each RDS size fraction $\left(F_{w}\right.$, \%). 
Table 3

GSF $_{\text {Load }}$ of each metal fraction in RDS and washoff particles in different sizes along the urban-rural gradient (GSF Load $\%{ }^{a}$.

\begin{tabular}{|c|c|c|c|c|c|c|c|}
\hline \multirow[t]{2}{*}{ Metal fractions } & \multirow[t]{2}{*}{ Urban-rural gradient ${ }^{b}$} & \multicolumn{2}{|l|}{$<105 \mu \mathrm{m}$} & \multicolumn{2}{|l|}{$105-250 \mu \mathrm{m}$} & \multicolumn{2}{|c|}{$250-1000 \mu \mathrm{m}$} \\
\hline & & $\mathrm{RP}^{\mathrm{c}}$ & WP & $\mathrm{RP}$ & WP & $\mathrm{RP}$ & WP \\
\hline \multirow[t]{2}{*}{ Acid- } & UCA & $55.9 \pm 28.2$ & $78.2 \pm 41.4$ & $28.5 \pm 19.8$ & $18.0 \pm 15.1$ & $15.6 \pm 10.2$ & $3.8 \pm 2.8$ \\
\hline & CSA & $44.5 \pm 9.4$ & $68.2 \pm 18.2$ & $45.1 \pm 8.1$ & $29.2 \pm 7.6$ & $10.4 \pm 3.7$ & $2.5 \pm 1.0$ \\
\hline \multirow[t]{3}{*}{ extractable } & RTA & $43.6 \pm 17.5$ & $74.3 \pm 23.1$ & $26.9 \pm 10.9$ & $16.5 \pm 8.0$ & $29.5 \pm 18.8$ & $9.3 \pm 8.2$ \\
\hline & RVA & $50.1 \pm 35.2$ & $72.6 \pm 33.4$ & $35.1 \pm 25.1$ & $23.3 \pm 19.0$ & $14.8 \pm 13.2$ & $4.1 \pm 4.1$ \\
\hline & UVA & $23.0 \pm 2.7$ & $51.5 \pm 7.7$ & $42.9 \pm 9.7$ & $36.1 \pm 7.9$ & $34.1 \pm 1.8$ & $12.4 \pm 0.8$ \\
\hline \multirow[t]{5}{*}{ Reducible } & UCA & $52.5 \pm 35.2$ & $75.3 \pm 49.6$ & $27.7 \pm 14.9$ & $18.7 \pm 12.8$ & $19.8 \pm 11.3$ & $6.0 \pm 5.4$ \\
\hline & CSA & $42.0 \pm 14.9$ & $66.6 \pm 19.5$ & $47.0 \pm 11.2$ & $30.7 \pm 11.0$ & $10.9 \pm 3.6$ & $2.7 \pm 1.2$ \\
\hline & RTA & $39.7 \pm 16.8$ & $72.8 \pm 19.4$ & $29.6 \pm 7.2$ & $18.3 \pm 6.0$ & $30.7 \pm 16.5$ & $8.9 \pm 6.1$ \\
\hline & RVA & $47.9 \pm 34.0$ & $71.3 \pm 31.2$ & $36.9 \pm 21.2$ & $24.5 \pm 16.9$ & $15.2 \pm 11.5$ & $4.1 \pm 3.6$ \\
\hline & UVA & $29.0 \pm 3.1$ & $57.1 \pm 5.2$ & $46.6 \pm 7.4$ & $35.3 \pm 5.2$ & $24.3 \pm 7.8$ & $7.6 \pm 3.4$ \\
\hline \multirow[t]{5}{*}{ Oxidizable } & UCA & $63.5 \pm 32.7$ & $86.2 \pm 45.2$ & $23.4 \pm 3.7$ & $11.1 \pm 2.1$ & $13.1 \pm 6.6$ & $2.7 \pm 1.4$ \\
\hline & CSA & $48.6 \pm 10.3$ & $75.6 \pm 14.3$ & $39.1 \pm 8.1$ & $21.4 \pm 5.4$ & $12.4 \pm 5.2$ & $3.0 \pm 1.6$ \\
\hline & RTA & $46.7 \pm 18.8$ & $76.6 \pm 16.3$ & $28.5 \pm 14.8$ & $16.6 \pm 10.9$ & $24.7 \pm 16.1$ & $6.8 \pm 6.2$ \\
\hline & RVA & $44.1 \pm 32.5$ & $68.2 \pm 31.5$ & $37.4 \pm 19.7$ & $25.9 \pm 17.0$ & $18.5 \pm 15.5$ & $5.9 \pm 6.3$ \\
\hline & UVA & $36.5 \pm 11.6$ & $63.6 \pm 16.8$ & $46.8 \pm 13.5$ & $32.0 \pm 14.0$ & $16.8 \pm 2.0$ & $4.4 \pm 0.3$ \\
\hline \multirow[t]{5}{*}{ Residual } & UCA & $63.8 \pm 24.2$ & $86.5 \pm 39.1$ & $23.6 \pm 6.6$ & $10.9 \pm 3.9$ & $12.6 \pm 3.2$ & $2.6 \pm 1.1$ \\
\hline & CSA & $48.0 \pm 12.8$ & $75.4 \pm 22.1$ & $42.7 \pm 8.4$ & $22.6 \pm 4.1$ & $9.3 \pm 3.1$ & $2.0 \pm 0.6$ \\
\hline & RTA & $49.9 \pm 20.6$ & $77.9 \pm 18.3$ & $31.4 \pm 21.9$ & $17.4 \pm 14.2$ & $18.7 \pm 10.0$ & $4.7 \pm 3.5$ \\
\hline & RVA & $54.0 \pm 30.4$ & $78.2 \pm 29.7$ & $30.7 \pm 18.2$ & $17.8 \pm 12.1$ & $15.2 \pm 11.6$ & $4.0 \pm 3.9$ \\
\hline & UVA & $34.5 \pm 10.0$ & $63.3 \pm 11.4$ & $44.9 \pm 10.2$ & $30.9 \pm 9.4$ & $20.6 \pm 3.7$ & $5.7 \pm 2.0$ \\
\hline \multirow[t]{5}{*}{ Total } & UCA & $63.0 \pm 29.1$ & $86.6 \pm 43.8$ & $23.9 \pm 4.2$ & $11.0 \pm 1.9$ & $13.2 \pm 4.2$ & $2.5 \pm 0.7$ \\
\hline & CSA & $49.9 \pm 7.6$ & $76.5 \pm 15.9$ & $40.5 \pm 5.1$ & $21.4 \pm 4.7$ & $9.6 \pm 3.6$ & $2.1 \pm 0.8$ \\
\hline & RTA & $47.8 \pm 19.3$ & $77.5 \pm 17.0$ & $29.3 \pm 16.6$ & $16.4 \pm 11.5$ & $22.9 \pm 13.7$ & $6.1 \pm 5.2$ \\
\hline & RVA & $52.0 \pm 31.6$ & $76.4 \pm 29.9$ & $32.6 \pm 18.4$ & $19.6 \pm 13.0$ & $15.3 \pm 12.0$ & $4.1 \pm 4.0$ \\
\hline & UVA & $33.7 \pm 7.7$ & $62.8 \pm 11.0$ & $46.2 \pm 9.2$ & $31.6 \pm 9.3$ & $20.1 \pm 2.9$ & $5.5 \pm 0.7$ \\
\hline
\end{tabular}

a The percentage of contributions of the RDS particle size fractions to the mean GSF $_{\text {Load }}$ of all studied metals was calculated by the combination of five metals percentage

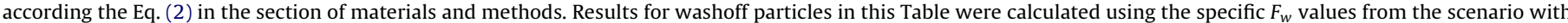
rainfall intensity of $46.7 \mathrm{~mm} / \mathrm{h}$ and duration of $1 \mathrm{~h}$.

b Urban-rural gradient: UCA = central urban area; UVA = urban village area; CSA = central suburban county area; RTA= rural town area; RVA= rural village area.

c RP: road-deposited sediment particles; WP: washoff particles.

Table 4

Metal concentrations of different fractions in washoff particles under three rainfall intensities and two duration periods in the central urban area (mg/kg).

\begin{tabular}{|c|c|c|c|c|c|c|c|c|}
\hline \multirow[t]{3}{*}{ Heavy metal } & \multirow[t]{3}{*}{ Chemical fractions } & \multicolumn{6}{|c|}{ Simulation rainfall intensities and durations } & \multirow[t]{3}{*}{ RDS } \\
\hline & & \multicolumn{2}{|l|}{$12.87 \mathrm{~mm} / \mathrm{h}$} & \multicolumn{2}{|l|}{$46.7 \mathrm{~mm} / \mathrm{h}$} & \multicolumn{2}{|l|}{$82.67 \mathrm{~mm} / \mathrm{h}$} & \\
\hline & & $0-10 \min$ & $0-60 \min$ & $0-10 \min$ & $0-60 \min$ & $0-10 \min$ & $0-60 \min$ & \\
\hline \multirow[t]{5}{*}{$\mathrm{Cr}$} & Acid-extractable & $3.0 \pm 2.1$ & $3.0 \pm 2.2$ & $3.3 \pm 2.7$ & $3.0 \pm 2.3$ & $3.1 \pm 2.4$ & $3.0 \pm 2.3$ & $2.6 \pm 1.5$ \\
\hline & Oxidizable & $19.4 \pm 22.4$ & $19.8 \pm 22.9$ & $20.7 \pm 25.3$ & $20.0 \pm 23.8$ & $20.3 \pm 24.8$ & $19.9 \pm 24.0$ & $6.7 \pm 3.4$ \\
\hline & Reducible & $12.1 \pm 5.0$ & $12.1 \pm 5.0$ & $13.4 \pm 6.2$ & $12.6 \pm 5.5$ & $13.1 \pm 5.9$ & $12.8 \pm 5.6$ & $13.3 \pm 3.4$ \\
\hline & Residual & $63.8 \pm 10.0$ & $64.4 \pm 10.0$ & $69.5 \pm 9.7$ & $65.1 \pm 10.1$ & $66.0 \pm 10.0$ & $64.3 \pm 9.8$ & $51.9 \pm 7.4$ \\
\hline & Total & $86.9 \pm 2.2$ & $87.7 \pm 2.3$ & $93.1 \pm 3.2$ & $88.5 \pm 1.0$ & $89.2 \pm 0.4$ & $87.4 \pm 0.7$ & $74.5 \pm 5.8$ \\
\hline \multirow[t]{5}{*}{$\mathrm{Cu}$} & Acid-extractable & $3.1 \pm 3.4$ & $3.1 \pm 3.3$ & $3.6 \pm 4.8$ & $3.4 \pm 4.0$ & $3.7 \pm 4.7$ & $3.7 \pm 4.4$ & $2.6 \pm 1.7$ \\
\hline & Oxidizable & $14.3 \pm 9.4$ & $14.1 \pm 9.3$ & $15.7 \pm 15.2$ & $14.6 \pm 11.7$ & $15.2 \pm 13.6$ & $15.2 \pm 12.1$ & $16.3 \pm 1.3$ \\
\hline & Reducible & $53.8 \pm 41.0$ & $53.9 \pm 40.9$ & $63.3 \pm 49.3$ & $57.0 \pm 44.2$ & $59.7 \pm 46.7$ & $57.2 \pm 44.3$ & $61.4 \pm 5.6$ \\
\hline & Residual & $21.5 \pm 12.1$ & $22.0 \pm 12.5$ & $24.0 \pm 11.6$ & $21.0 \pm 10.7$ & $20.1 \pm 9.6$ & $19.1 \pm 9.5$ & $16.1 \pm 6.9$ \\
\hline & Total & $118.4 \pm 2.2$ & $118.5 \pm 0.2$ & $135.3 \pm 24.7$ & $123.2 \pm 12.5$ & $127.0 \pm 21.3$ & $122.5 \pm 16.0$ & $96.3 \pm 7.0$ \\
\hline \multirow[t]{5}{*}{$\mathrm{Ni}$} & Acid-extractable & $5.8 \pm 1.7$ & $5.9 \pm 1.7$ & $6.7 \pm 1.8$ & $5.9 \pm 1.4$ & $5.9 \pm 1.2$ & $5.7 \pm 1.2$ & $4.5 \pm 1.5$ \\
\hline & Oxidizable & $8.6 \pm 9.3$ & $9.1 \pm 10.1$ & $7.0 \pm 6.1$ & $8.7 \pm 9.3$ & $8.1 \pm 8.2$ & $8.4 \pm 8.8$ & $2.8 \pm 1.6$ \\
\hline & Reducible & $3.2 \pm 1.4$ & $3.3 \pm 1.5$ & $3.6 \pm 1.6$ & $3.4 \pm 1.5$ & $3.5 \pm 1.6$ & $3.4 \pm 1.6$ & $2.1 \pm 0.7$ \\
\hline & Residual & $11.4 \pm 6.4$ & $11.7 \pm 6.6$ & $12.6 \pm 7.1$ & $11.6 \pm 6.4$ & $11.5 \pm 6.2$ & $11.0 \pm 5.9$ & $8.74 \pm 3.4$ \\
\hline & Total & $23.0 \pm 5.6$ & $23.4 \pm 5.8$ & $25.5 \pm 5.4$ & $23.5 \pm 5.5$ & $23.5 \pm 5.3$ & $22.7 \pm 5.2$ & $18.0 \pm 2.8$ \\
\hline \multirow{5}{*}{$\mathrm{Pb}$} & Acid-extractable & $7.6 \pm 0.2$ & $7.8 \pm 0.0$ & $7.4 \pm 1.3$ & $7.3 \pm 0.9$ & $7.1 \pm 1.2$ & $7.1 \pm 0.9$ & $6.3 \pm 0.4$ \\
\hline & Oxidizable & $15.2 \pm 5.8$ & $15.2 \pm 6.0$ & $16.2 \pm 6.6$ & $15.2 \pm 5.5$ & $15.2 \pm 5.2$ & $15.0 \pm 4.8$ & $15.0 \pm 4.4$ \\
\hline & Reducible & $17.2 \pm 3.1$ & $17.3 \pm 3.0$ & $19.8 \pm 3.8$ & $18.0 \pm 3.9$ & $18.7 \pm 4.5$ & $18.0 \pm 4.4$ & $14.1 \pm 6.9$ \\
\hline & Residual & $15.7 \pm 4.0$ & $16.0 \pm 3.9$ & $15.9 \pm 6.7$ & $15.8 \pm 4.3$ & $15.2 \pm 5.2$ & $14.8 \pm 4.6$ & $14.2 \pm 2.3$ \\
\hline & Total & $56.6 \pm 8.2$ & $57.2 \pm 8.5$ & $58.8 \pm 6.6$ & $56.7 \pm 8.1$ & $55.9 \pm 7.2$ & $54.7 \pm 7.6$ & $49.5 \pm 13.9$ \\
\hline \multirow[t]{5}{*}{$\mathrm{Zn}$} & Acid-extractable & $128.5 \pm 2.6$ & $129.1 \pm 2.9$ & $139.3 \pm 13.4$ & $128.3 \pm 5.5$ & $128.2 \pm 7.9$ & $124.8 \pm 5.2$ & $112.3 \pm 9.3$ \\
\hline & Oxidizable & $60.8 \pm 27.2$ & $61.4 \pm 28.3$ & $71.2 \pm 25.2$ & $62.3 \pm 26.8$ & $63.6 \pm 24.9$ & $60.3 \pm 24.0$ & $48.9 \pm 18.8$ \\
\hline & Reducible & $75.5 \pm 10.2$ & $76.0 \pm 10.9$ & $86.0 \pm 9.3$ & $76.8 \pm 6.3$ & $77.6 \pm 1.4$ & $74.8 \pm 5.1$ & $76.0 \pm 4.1$ \\
\hline & Residual & $80.4 \pm 12.7$ & $80.6 \pm 11.9$ & $89.9 \pm 15.4$ & $82.0 \pm 14.8$ & $83.6 \pm 17.4$ & $80.9 \pm 17.2$ & $67.4 \pm 16.3$ \\
\hline & Total & $360.0 \pm 17.2$ & $362.9 \pm 17.4$ & $386.6 \pm 4.7$ & $360.6 \pm 14.1$ & $358.8 \pm 8.8$ & $349.3 \pm 9.7$ & $304.6 \pm 6.3$ \\
\hline
\end{tabular}


fractions in RDS and washoff particles using rainfall simulation and found increases in washoff particles when compared with those in RDS of 10-30\%. Different metals showed increased percentages in different chemical fractions. Moreover, we found that the increased percentages of metals in washoff particles were not affected by rainfall intensity and duration. These findings implied that the particle size composition of washoff particles was not affected by rainfall intensity and duration, which could be attributed to the fact that the $F_{w}$ of each particle size varied proportionally to the rainfall intensity and duration (Fig. 5). Although rainfall intensity and duration affected the amount of RDS and their associated metals in washoff water [5,6], solid phase concentrations of heavy metal in washoff particles did not vary throughout the entire washoff process. Clearly, our findings should contribute to quantification of the relationship between heavy metal pollutants in RDS and washoff particles.

The equation used in our washoff calculations was developed without considering the distance traveled by the RDS or the slope and roughness of the road. In a pre-experiment for RDS washoff, we found that smoothness of roads strongly affected the proportion of each particle size fraction of RDS, and that the amount and particle size composition of RDS also varied with road smoothness [39]. It is unknown how road smoothness and particle size composition interactively affect metal pollutants in washoff particles. The first flush could make a greater contribution to washoff pollution on smoother roads because of its higher $F_{w}$ values. This is because rainfall is stronger at the start of the storm, but becomes a less important factor as the availability of easily detachable and transportable fractions of the surface pollutant decreases during the storm [40]. Future studies should consider how the road smoothness affects the relationship of heavy metals with different chemical fractions between RDS and washoff particles. In addition, all results of washoff particles in this study were based on simulated rainfall experiments; therefore, the findings presented herein should be verified based on natural rainfall in future studies [41].

\section{Conclusion}

We conducted a washoff experiment using simulated rainfall and RDS samples collected from a rapid urbanization area that had a clear urban-rural gradient pattern. Both RDS samples and washoff particle samples were analyzed for the amounts, particle size composition and metals concentrations in different chemical fractions for each particle size. The urban-rural gradient had an important impact on the relationships between pollutants in RDS and washoff particles via the quantity, particle size, particle mobility of RDS and pollutants associated with them. Along the urban-rural gradient, heavy metal concentrations with different chemical fractions in RDS and washoff particles and the percentage of RDS mobility caused by washoff decreased. The RDS and washoff amount per unit area increased along the urban-rural gradient. We found that heavy metal concentrations in washoff particles increased by $10-30 \%$ when compared with RDS because storm runoff selectively transported RDS with different particle sizes. However, the rate at which metals concentrations increased was not affected by rainfall intensities and durations due to the invariable particle size composition of the washoff. The contribution of particles with different particle sizes to the overall contamination differed between the RDS and washoff particles, with smaller washoff particles accounting for a larger proportion of particle size and heavy metal contribution than the corresponding particles in RDS. Overall, our findings will help explain the relationships between pollution in RDS and washoff particles along urban-rural gradients.

\section{Acknowledgements}

We thank Xiaoyan He, Xiaomei Wang, Xiaoxue Wang, Huiliang Wang, Yang Ouyang, Xinzhong Du, Wenzan Li, and Shuxia He for their help collecting road-deposited sediment and with the rainfall simulation experiments. Funding was supported by the National Natural Science Foundation of China (no. 41171395 \& 40971271) and the State Key Development Program for Basic Research of China (no. 2009CB421104).

\section{References}

[1] S. Charlesworth, M. Everett, R. McCarthy, A. Ordonez, E. de Miguel, A comparative study of heavy metal concentration and distribution in deposited street dusts in a large and a small urban area: Birmingham and Coventry, West Midlands, UK, Environ. Int. 29 (2003) 563-573.

[2] K. Adachi, Y. Tainosho, Single particle characterization of size-fractionated road sediments, Appl. Geochem. 20 (2005) 849-859.

[3] R.A. Sutherland, Lead in grain size fractions of road-deposited sediment, Environ. Pollut. 121 (2003) 229-237.

[4] H. Zhao, X. Li, X. Wang, D. Tian, Grain size distribution of road-deposited sediment and its contribution to heavy metal pollution in urban runoff in Beijing, China, J. Hazard. Mater. 183 (2010) 203-210.

[5] L. Herngren, A. Goonetilleke, G.A. Ayoko, Understanding heavy metal and suspended solids relationships in urban stormwater using simulated rainfall, J. Environ. Manage. 76 (2005) 149-158.

[6] H. Zhao, X. Li, X. Wang, Heavy metal content of road-deposited sediment along the urban-rural gradient around Beijing and its potential contribution to runoff pollution, Environ. Sci. Technol. 145 (2011) 7120-7127.

[7] P. Egodawatta, E. Thomas, A. Goonetilleke, Mathematical interpretation of pollutant wash-off from urban road surfaces using simulated rainfall, Water Res. 41 (2007) 3025-3031.

[8] S.L. Lau, M.K. Stenstrom, Metals, and PAHs adsorbed to street particles, Water Res. 39 (2005) 4083-4092.

[9] M. Murakami, F. Nakajima, H. Furumai, Modelling of runoff behaviour of particle-bound polycyclic aromatic hydrocarbons (PAHs) from roads and roofs, Water Res. 38 (2004) 4475-4483.

[10] C. Pagotto, N. Remy, M. Legret, P. Le Cloirec, Heavy metal pollution of road dust and roadside soil near a major rural highway, Environ. Technol. 22 (2001) 307-319.

[11] Z. Haiping, K. Yamada, Estimation for urban runoff quality modeling, Water Sci. Technol. 34 (1996) 49-54.

[12] H. Furumai, H. Balmer, M. Boller, Dynamic behavior of suspended pollutants and particle size distribution in highway runoff, Water Sci. Technol. 46 (2002) 413-418.

[13] J.Y. Kim, J.J. Sansalone, Event-based size distributions of particulate matter transported during urban rainfall-runoff events, Water Res. 42 (2008) 2756-2768.

[14] D.J. Robertson, K.G. Taylor, Temporal variability of metal contamination in urban road-deposited sediment in Manchester, UK: implications for urban pollution monitoring, Water Air Soil Pollut. 186 (2007) 209-220.

[15] K.N. Irvine, M.F. Perrelli, R. Ngoen-klan, I.G. Droppo, Metal levels in street sediment from an industrial city: spatial trends, chemical fractionation, and management implications, J. Soil Sediment 9 (2009) 328-341.

[16] E. Manno, D. Varrica, G. Dongarra, Metal distribution in road dust samples collected in an urban area close to a petrochemical plant at Gela, Sicily, Atmos. Environ. 40 (2006) 5929-5941.

[17] S.B. Shaw, M.T. Walter, T.S. Steenhuis, A physical model of particulate wash-off from rough impervious surfaces, J. Hydrol. 327 (2006) 618-626.

[18] P. Soonthornnonda, E.R. Christensen, Y. Liu, J. Li, A washoff model for stormwater pollutants, Sci. Total Environ. 402 (2008) 248-256.

[19] J.D.B.G.B. Sartor, F.J. Agardy, Water pollution aspects of street surface contaminants, J. Water Pollut. Control Fed. 46 (1974) 458-467.

[20] S. Kartal, Z. Aydin, S. Tokalioglu, Fractionation of metals in street sediment samples by using the BCR sequential extraction procedure and multivariate statistical elucidation of the data, J. Hazard. Mater. 132 (2006) 80-89.

[21] J.J. McAlister, B.J. Smith, J.B. Neto, J.K. Simpson, Geochemical distribution and bioavailability of heavy metals and oxalate in street sediments from Rio de Janeiro, Brazil: a preliminary investigation, Environ. Geochem. Health 27 (2005) 429-441.

[22] E. Callender, K.C. Rice, The urban environmental gradient: anthropogenic influences on the spatial and temporal distributions of lead and zinc in sediments, Environ. Sci. Technol. 34 (2000) 232-238.

[23] Administrative divisions of the People's Republic of China. http://en.wikipedia. org/wiki/Administrative_divisions_of_the_People\%27s_Republic_of_China. [accessed 28.08.12].

[24] F.F. Deng, Y. Huang, Uneven land reform and urban sprawl in China: the case of Beijing, Prog. Plan. 61 (2004) 211-236.

[25] Y. Xie, X. Lin, Y. Liu, Y. Zheng, B. Liu, G. Zhang, Calibration of simulated rainfall intensity and its spatial distribution for trough rainfall simulator, B, Soil Water Conserv. 28 (2008) 1-6 (in Chinese). 
[26] J.J. Sansalone, S.G. Buchberger, S.R. Al-Abed, Fractionation of heavy metals in pavement runoff, Sci. Total Environ. 189 (1996) 371-378.

[27] G. Rauret, J. Lopez-Sanchez, A. Sahuquillo, R. Rubio, C. Davidson, A. Ure, P. Quevauviller, Improvement of the BCR three step sequential extraction procedure prior to the certification of new sediment and soil reference materials, J. Environ. Monit. 1 (1999) 57-61.

[28] A. Sahuquillo, J.F. LoÂpez-SaÂnchez, R. Rubio, G. Rauret, R.P. Thomas, C.M. Davidson, A.M. Ure, Use of a certified reference material for extractable trace metals to assess sources of uncertainty in the BCR three-stage sequential extraction procedure, Anal. Chim. Acta 382 (1999) 317-327.

[29] R.A. Sutherland, F.M.G. Tack, Determination of $\mathrm{Al}, \mathrm{Cu}, \mathrm{Fe}, \mathrm{Mn}, \mathrm{Pb}$ and $\mathrm{Zn}$ in certified reference materials using the optimized BCR sequential extraction procedure, Anal. Chim. Acta 454 (2002) 249-257.

[30] A. Tessier, P.G.C. Campbell, M. Bisson, Sequential extraction procedure for the speciation of particulate trace metals, Anal. Chem. 51 (1979) 844-851.

[31] J.R. Graney, T.M. Eriksen, Metals in pond sediments as archives of anthropogenic activities: a study in response to health concerns, Appl. Geochem. 19 (2004) 1177-1188.

[32] R. Pitt, Demonstration of nonpoint pollution abatement through improved street cleaning practices, Report No. EPA-600/2-79-161, U.S. Environmental Protection Agency, Cincinnati, OH, 1979.

[33] J.D. Sartor, G.B. Boyd, Water pollution aspects of street surface contaminants, Report No. EPA-R2-72/081, U.S. Environmental Protection Agency, Washington, D.C., 1972.
[34] J. Sansalone, G. Ying, Partitioning and granulometric distribution of metal leachate from urban traffic dry deposition particulate matter subject to acidic rainfall and runoff retention, Water Res. 42 (2008) 4146-4162.

[35] W.C. Huber, R.E. Dickinson, Storm Water Management Model, Version 4: User's Manual, U.S. Environmental Protection Agency, Athens, G.A, 1988.

[36] R.G. Millar, Analytical determination of pollutant wash-off parameters, J. Environ. Eng. 125 (1999) 989-992.

[37] R.K. Aryal, H. Furumai, F. Nakajima, M. Boller, Dynamic behavior of fractional suspended solids and particle-bound polycyclic aromatic hydrocarbons in highway runoff, Water Res. 39 (2005) 5126-5134.

[38] C.S. Eckley, B. Branfireun, Simulated rain events on an urban roadway to understand the dynamics of mercury mobilization in stormwater runoff, Water Res. 43 (2009) 3635-3646

[39] R. Pitt, D. Williamson, J. Voorhees, S. Clark, Review of historical street dust and dirt accumulation and washoff data, in: W. James, K.N. Irvine, E.A. McBean, R.E. Pitt (Eds.), Effective Modeling of Urban Water Systems, Monograph 13, CHI, Guelph, Ontario, 2005, pp. 203-246.

[40] J. Vaze, F.H.S. Chiew, Study of pollutant washoff from small impervious experimental plots, Water Resour. Res. 39 (2003) 1160-1169.

[41] A.J. Parsons, S.G.L. Stromberg, Experimental analysis of size and distance of travel of unconstrained particles in interrill flow, Water Resour. Res. 34 (1998) 2377-2381. 